\title{
The dentist's role in diagnosing craniofacial dysostosis
}

\author{
Aruna Kanaparthy, Rosaiah Kanaparthy, Sanjeev Tyagi, Yogesh Gupta
}

\section{ABSTRACT}

Introduction: The Crouzon syndrome is a rare clinical condition that affects the craniofacial skeleton development. It accounts for about 4.8\% of all the cases of craniosynostosis, and it is the most common syndrome presenting with craniosynostoses. The Crouzon syndrome's early diagnosis is critical to avoid cranial hypertension as well as visual disturbances and blindness. Children who have Crouzon syndrome have a range of problems of variable severity, from mild facial defects causing a primarily cosmetic concern, to severe symptoms affecting breathing, feeding, vision and brain development. The dental profession should have sufficient knowledge of syndromes associated with dysmorphic facies to detect patients who

Aruna Kanaparthy ${ }^{1}$, Rosaiah Kanaparthy ${ }^{2}$, Sanjeev Tyagi ${ }^{3}$, Yogesh Gupta 4

Affiliations: ${ }^{1} \mathrm{BDS}, \mathrm{MDS}$, Reader, Dept of Conservative Dentistry \& Endodontics. Peoples Dental Academy, Bhopal-462037, Madhya Pradesh, HIG-3, PDA Staff quarters, Peoples campus, Bhanpur, Bhopal; ${ }^{2} \mathrm{BDS}, \mathrm{MDS}$, Professor \& HOD. Dept of periodontics, Peoples Dental Academy, Bhopal-462037, Madhya Pradesh, HIG-3, PDA Staff quarters, Peoples campus, Bhanpur, Bhopal; ${ }^{3} B D S$, MDS, Professor \& HOD Dept of Conservative Dentistry \& Endodontics. Peoples Dental Academy, Bhopal-462037, Madhya Pradesh, HIG-11, PDA Staff quarters, Peoples campus, Bhanpur, Bhopal; ${ }^{4}$ BDS, MDS, Professor, Dept of Orthodontics. RKDF Dental College \& Hospital, Bhopal462037, Madhya Pradesh, Peoples campus, Bhanpur, Bhopal.

Corresponding Author: Dr. Rosaiah Kanaparthy, BDS, MDS, Professor \& HOD. Dept of periodontics, Peoples Dental Academy, Bhopal-462037, Madhya Pradesh, HIG3, PDA Staff quarters, Peoples campus, Bhanpur, Bhopal; Mob: +919893050554; Email: drrosaiah@gmail.com, medha98@gmail.com

Received: 07 August 2012

Accepted: 16 November 2012

Published: 01 May 2013 are unaware of their condition. Case Report: A 23-year-old female patient presented to the clinic with multiple dental problems affecting masticatory efficiency and esthetics. On observation, it was seen that she had many facial and dental deformities which were suggestive of craniofacial dysostosis. The case was diagnosed as Crouzon syndrome. Conclusion: This case report emphasizes the role of a dentist in diagnosing such conditions and coordinating a multi-disciplinary team for corrective measures.

Keywords: Craniosynostoses, Crouzon syndrome, Craniofacial dysostosis, Exophthalmia, Facial defects

$$
* * * * * * * * *
$$

Kanaparthy A, Kanaparthy R, Tyagi S, Gupta Y. The dentist's role in diagnosing craniofacial dysostosis. International Journal of Case Reports and Images 2013;4(5):255-259.

$$
* * * * * * * * *
$$

doi:10.5348/ijcri-2013-05-307-CR-4

\section{INTRODUCTION}

Crouzon syndrome was originally described in 1912 by a French neurologist. He described four essential characteristics: exorbitism, retromaxillism, inframaxillism and paradoxic retrognathia. The incidence of this syndrome appears to be approximately one in 25,000 in the general population. It is inherited in an autosomal dominant pattern with variable expression. The mutation in the genes that codify type 2 fibroblast growth factor receptor (FGFR2), is responsible for the deformities observed. However, about 50\% new cases of Crouzon syndrome are not 
inherited but result from new spontaneous mutations [1-6]. Crouzon syndrome is characterized by craniosynostosis, maxillary hypoplasia, shallow orbits with proptosis and bifid uvula. There are often intracranial abnormalities such as anomalous venous drainage and hydrocephalus. A variety of other manifestations of Crouzon syndrome exist, including calcification of the stylohyoid ligament in 50\% patients over four years old, cervical spine abnormalities in up to $40 \%$ patients, elbow malformations (18\%), minor hand deformities (10\%), visceral anomalies (7\%), various musculoskeletal deformities (7\%), and skin lesions. Stylohyoid ligament calcification is also reported in 38-88\% cases of Apert syndrome. Cervical spine fusion anomalies affecting $\mathrm{C}_{2}$ to $\mathrm{C}_{5}$ are the most common vertebral deformities in Crouzon syndrome. Limb anomalies in Crouzon syndrome are nonspecific. Acanthosis nigrans (hyperpigmented, hyperkeratotic lesions located on the neck and near joint flexures) has also been reported in Crouzon syndrome [7, 8]. Treatment of craniofacial syndromes consists of a team approach in which each organ system is addressed independently and problems are prioritized on the basis of relative urgency.

\section{CASE REPORT}

A 23-year-old female patient reported to the dental clinic with the chief complaint of pain in 36 since the past two days and also expressed concern about her difficulty in mastication and lack of dental and facial harmony. The patient's sister also had similar problems but was not available for examination. Medical history was insignificant and the patient appeared to have normal mental faculties. On clinical examination, the patient presented with the typical manifestations of craniofacial dysostosis. Brachycephalic head form, prominent forehead, concave profile, decreased malar prominence, ocular proptosis, hypoplastic midface, exophthalmos, hypertelorism, beak like nose (psittichornia), low set ears, excessive lower facial height, maxillary retrognathism and a short upper lip. (Figures 1-3) Intraoral examination revealed Class III dental relationship, narrow, v-shaped maxilla, higharched palate, bilateral posterior crossbite, spacing between upper anterior teeth, malocclusion, oligodontia with missing 21, 32, 42, 35, 45, 47 teeth submerged, retained deciduous 85 , tender to touch 36 with deep caries. Patient gave history of recent extraction of retained 75 .

Periodontal status was normal. The set of records obtained were study casts; posteroanterior skull, wrist and panoramic radiographs; and photographs. The skull radiograph presented with a copper-beaten appearance. Wrist radiographs were normal. The panoramic radiograph showed retained deciduous submerged tooth 85 , tilted teeth, edentulous space in the third quadrant, missing 21, 32, 35, 42, 45, 47 along with periapical lesions in relation to 26 and 31. (Figures 4-6) The diagnosis for 36 was irreversible pulpitis and endodontic treatment was initiated. The patient was counseled about the craniofacial condition she was suffering from and treatment possibilities explained. She was referred to a plastic surgeon, an oral surgeon an ophthalmologist, an orthodontist and a prosthodontist working independently for further evaluation and action.

\section{DISCUSSION}

Crouzon syndrome is inherited as a highly variable autosomal dominant condition, and approximately half the cases are familial. About 30 different mutations of fibroblast growth factor receptor II have been identified in Crouzon syndrome. The Crouzon phenotype is highly variable and ranges from ocular proptosis and midface hypoplasia with no craniosynostosis to a cloverleaf skull deformity. Unlike most other craniofacial syndromes caused by fibroblast growth factor receptor mutations the limbs are typically unaffected [9]. The fibroblast growth factors are intrinsically related to the extracellular matrix formation. When the extracellular matrix presents FGFR2' mutation, it begins to secrete cytokines both in autocrinous and paracrinous manner and these may modify the matrix. In this disease, the premature closure of cranial sutures and midfacial sutures give it a brachiocephalic configuration $[10,11]$. There is an underdeveloped midface with receded cheekbones. The patients appear exopthalmic due to the shallow orbits. They exhibit an Angle Class III malocclusion due to the midface deficiency, while the mandibular growth potential is normal. Najal airway obstruction may occur because of the underdeveloped midface and high arched palate.

The obstruction of the upper respiratory passages develops following the septal diversion, abnormalities to the center of the nose and epipharynx narrowing. It can lead to acute respiratory anxiety, polyapnea and even

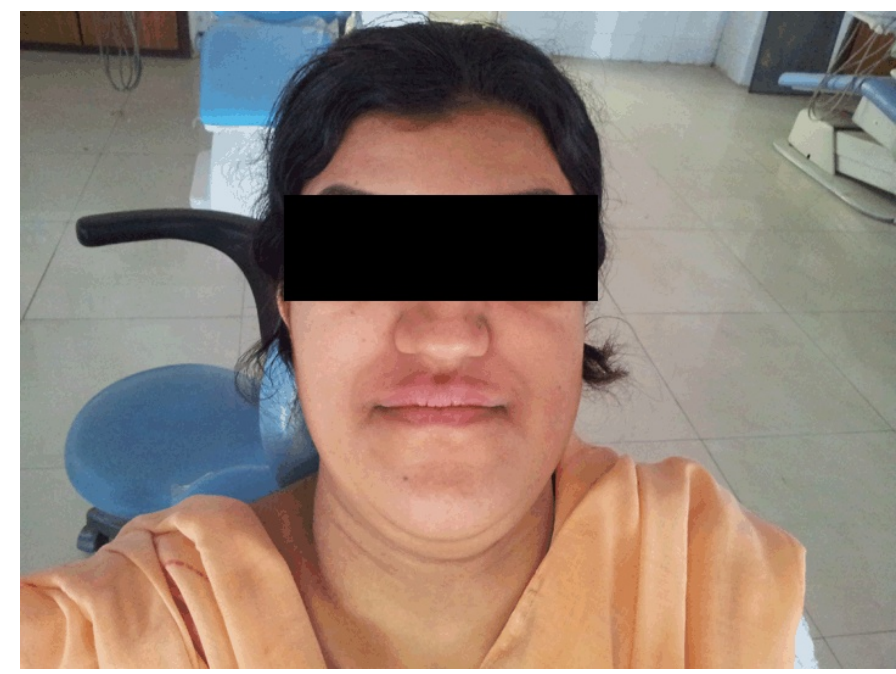

Figure 1: Front view of patient showing Brachycephalic head form best seen from the superior end-on or lateral view. The features include prominent forehead, decreased malar prominence, ocular proptosis, hypoplastic midface and hypertelorism. 


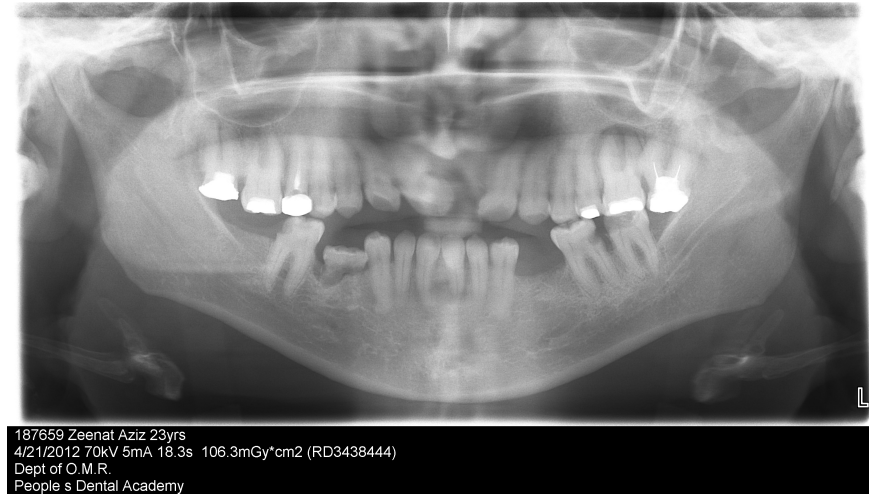

Figure 4: Orthopentogram shows missing 21, 32, 42, 35, 45, 47 teeth retained deciduous 85, spacing between upper anteriors, edentulous area in III quadrant, periapical radiolucencies in relation to 26, 31 and deep caries in relation to tooth 36 .

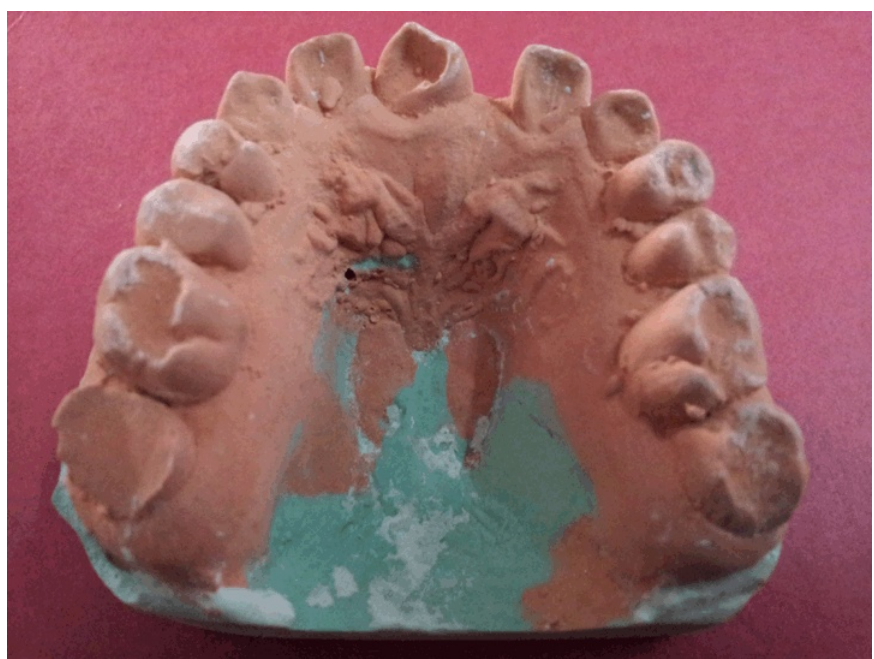

Figure 5: Dental cast shows narrow, v-shaped maxilla, higharched palate, upper anterior spacing and missing tooth 21.

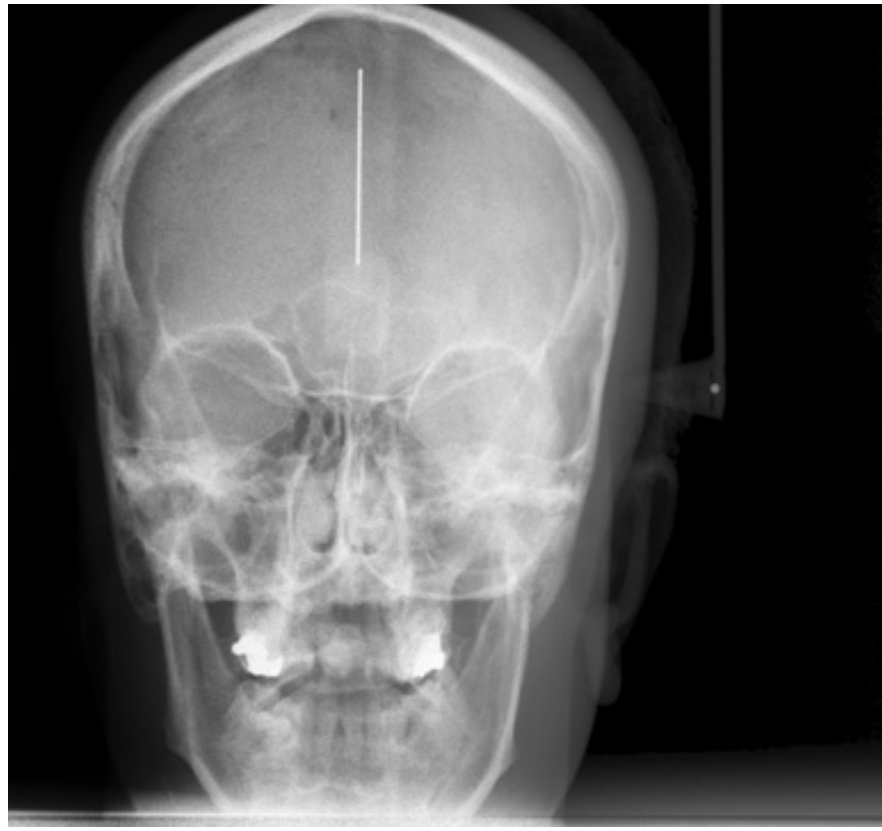

Figure 6: The skull radiograph showes a copper-beaten appearance. 
The conductive hearing loss is common due to the middle ear deformities.

There are several ocular abnormalities and the most common are shallow orbits, bilateral ocular proptosis, hypertelorism, divergent strabismus, optical atrophy, conjunctivitis or exposure keratoconjunctivitis and a non-explained loss of visual accuracy. Rarely nystagmus, coloboma of the iris, anisocoria, microcornea or megalocornea, cataract, blue sclerae, glaucoma and globe luxation may occur. Blindness following optical atrophy by the intracranial hypertension may also occur Spectaclesplasty en bloc rotation advancement of the periorbital bony skeleton can be safely performed before skeletal maturity which produces a more normal anatomic position of the periorbital soft tissues facilitating both function and aesthetics. Mental capacity is usually normal. An early craniosynostosis, evidenced by the existence of intracranial hypertension, is present in $60 \%$ cases and furnishes a reserved visual prognosis. The patients have hyperemia, and bilateral ocular irritation [12]. Diagnosis of Crouzon syndrome can be made at birth by assessing the signs and symptoms of the baby. Further analysis, including radiographs, magnetic resonance imaging (MRI) scans, genetic testing, X-rays and CT scans can be used to confirm the diagnosis of Crouzon syndrome [7]. Treatment of Crouzon syndrome is complex, since there are many aspects of the syndrome which require management. Crouzon syndrome almost always requires surgery to enable the skull to expand properly and to align the jaws, along with other surgeries to repair face and ear defects. The entire middle portion of the face may be surgically extended forward by various surgical techniques. Once treated for the cranial vault symptoms, Crouzon patients generally go on to live a normal lifespan [13].

\section{CONCLUSION}

Crouzon syndrome exhibit defects which resemble several other syndromes, a detailed case history, early diagnosis, exhaustive clinical, radiologic and genetic evaluation and comprehensive treatment plan is mandatory. This is better facilitated in a craniofacial center with multi-disciplinary health care staff who can collectively monitor the patient's progress.

$* * * * * * * * *$

\section{Author Contributions}

Aruna Kanaparthy - Substantial contributions to conception and design, Acquisition of data, Analysis and interpretation of data, Drafting the article, Revising it critically for important intellectual content, Final approval of the version to be published

Rosaiah Kanaparthy - Acquisition of data, Drafting the article, Revising it critically for important intellectual content, Final approval of the version to be published Sanjeev Tyagi - Acquisition of data, Drafting the article, Revising it critically for important intellectual content, Final approval of the version to be published
Yogesh Gupta - Acquisition of data, Drafting the article, Revising it critically for important intellectual content, Final approval of the version to be published

\section{Guarantor}

The corresponding author is the guarantor of submission.

\section{Conflict of Interest}

Authors declare no conflict of interest.

\section{Copyright}

(C) Aruna Kanaparthy et al. 2013; This article is distributed under the terms of Creative Commons Attribution 3.0 License which permits unrestricted use, distribution and reproduction in any means provided the original authors and original publisher are properly credited. (Please see www.ijcasereportsandimages.com /copyright-policy.php for more information.)

\section{REFERENCES}

1. Bowling EL, Burstein FD. Crouzon syndrome. Optometry 2006;77(5):217-2.

2. Eswarakumar VP, Horowitz MC, Locklin R, MorrissKay GM, Lonai P. A gain-of-function mutation of Fgfr2c demonstrates the roles of this receptor variant in osteogenesis. Proc Natural Acad Sci 2004;101(34):12555-60.

3. Hoefkens MF, Vermeij-Keers C, Vaandrager JM. Crouzon Syndrome: Phenotypic Signs and Symptoms of the Postnatally Expressed Subtype. Journal of Craniofac Surgery 2004;15(2):233-40.

4. Rice DP. Clinical features of syndromic craniosynostosis. Front Oral Biology 2008;12:91-106.

5. Cohen MM Jr, Kreiborg S. Birth prevalence studies of the Crouzon syndrome: comparison of direct and indirect methods. Clin Genet 1992;41(1):12-5.

6. Reardon W, Winter RM, Rutland P, Pulleyn LJ, Jones BM, Malcolm S. Mutations in the fibroblast growth factor receptor 2 gene cause Crouzon syndrome. Nature Geneicst 1994;8(1):98-103.

7. Lisa H Lowe, Timothy N Booth, Jeanne M Joglar, Nancy K Rollins. Midface anomalies in children. Radiographics 2000;20(4):907-22.

8. Prowdman TW, Moore MH, Abbott AH, David DJ. Noncraniofacial manifestations of Crouzon's disease. Journal of Craniofacial Surgery 1994;5(4):218-2.

9. Kreiborg S. Craniofacial growth in plagiocephaly and Crouzon syndrome. Scand Journal of Plastic Reconstractive Surgery 1981;15(3):187-97.

10. Carinci F, Pezzetti F, Locci P, et al. Apert and Crouzon Syndromes: Clinical Findings, Genes and Extracellular Matrix. Journal of Craniofacial Surgery 2005;16(3):361-8.

11. Ousterhout DK, Zlotolow IM. Aesthetic improvement of the forehead utilizing methylmethacrylate onlay implants. Aesthetic Plast Surg 1990;14(4):281-5.

12. Singer SL, Walpole I, Brogan WF, Goldblatt J. Dentofacial features of a family with Crouzon syndrome. Case reports. Australian Dental Journal 1997;42(1):11-7. 
13. Dorivaldo Lopes da Silva, Francisco Xavier Palheta Neto, Stéphanie Gonçalves Carneiro, Angélica Cristina Pezzin Palheta, Marcela Monteiro, Sarah Crestian Cunha, Cláudio Tobias Acatauassú Nunes. Crouzon's syndrome: literature review. International Arch Otorhinolaryngology 2008;12(3):436-1.

Access full text article on other devices

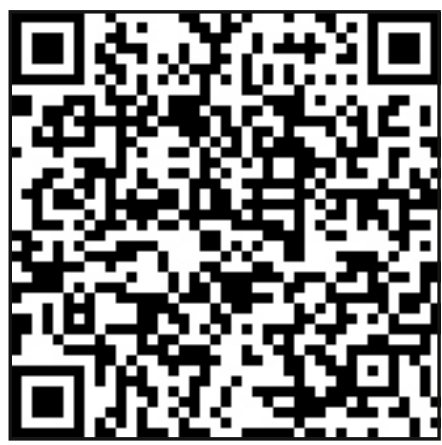

Access PDF of article on other devices

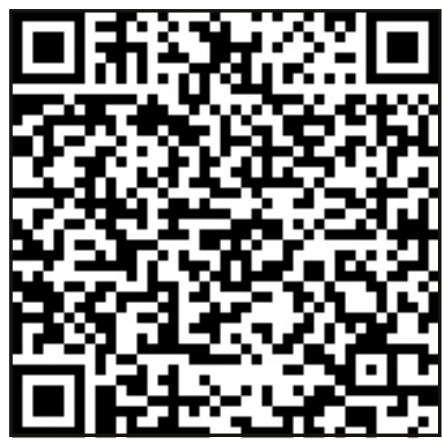

